Janet E. Spittler

\title{
Animals in the Apocryphal Acts of the Apostles
}

\author{
The Wild Kingdom of Early Christian Literature
}

[Tiere in den apokryphen Apostelakten. Das wilde Königreich in der frühchristlichen Literatur.]

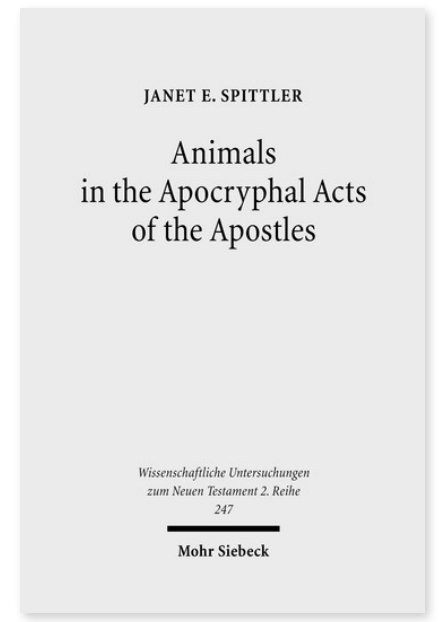

2008. XI, 264 Seiten. WUNT II 247

ISBN 978-3-16-151590-3

DOI 10.1628/978-3-16-151590-3

eBook PDF 79,00€

ISBN 978-3-16-149731-5

fadengeheftete Broschur 79,00€
Veröffentlicht auf Englisch.

Tiere spielen eine herausragende, oft sonderbare Rolle in den fünf sehr unterhaltsamen und bedeutenden apokryphen Apostelakten, den Andreasakten, Johannesakten, Petrusakten, Paulusakten und den Thomasakten. Löwen, Bären, Hunde, Kakerlaken, Esel und sogar Robben kommen in diesen Erzählungen vor. Manche sind freundlich, manche böswillig und manche besitzen die Fähigkeit zu sprechen. Janet E. Spittler zeigt, dass diese Tierepisoden eine größere und viel komplexere Bedeutung haben als bisher angenommen. Sie liest diese Texte im Kontext der griechisch-römischen Naturgeschichte, Philosophie, den Fabeln sowie Prosatexten und präsentiert neue Interpretationen der jeweiligen tierbezogenen Episode.

Janet E. Spittler Born 1976; 2007 PhD; since 2017 Associate Professor of Religious Studies, University of Virginia; Research Associate at the Department of Greek, Latin, and Classical Studies, University of the Free State, Bloemfontein, South Africa. https://orcid.org/0000-0002-3553-266X

\section{Jetzt bestellen:}

https://mohrsiebeck.com/buch/animals-in-the-apocryphal-acts-of-the-apostles-9783161515903?no_cache=1 order@mohrsiebeck.com

Telefon: +49 (0)7071-923-17

Telefax: +49 (0)7071-51104 